\title{
A novel gene, $L G I 1$, from 10q24 is rearranged and downregulated in malignant brain tumors
}

\author{
Olga B Chernova ${ }^{1}$, Robert PT Somerville ${ }^{1}$ and John K Cowell*,1 \\ ${ }^{1}$ Department of Neurosciences NC30, The Lerner Research Institute, The Cleveland Clinic Foundation, 9500 Euclid Avenue, \\ Cleveland, Ohio 44195, USA
}

\begin{abstract}
Loss of heterozygosity for $10 q 23-26$ is seen in over $80 \%$ of glioblastoma multiforme tumors. We have used a positional cloning strategy to isolate a novel gene, LGII (Leucine-rich gene-Glioma Inactivated), which is rearranged as a result of the $t(10 ; 19)(q 24 ; q 13)$ balanced translocation in the T98G glioblastoma cell line lacking any normal chromosome 10 . Rearrangement of the $L G I I$ gene was also detected in the A172 glioblastoma cell line and several glioblastoma tumors. These rearrangements lead to a complete absence of $L G I 1$ expression in glioblastoma cells. The $L G I 1$ gene encodes a protein with a calculated molecular mass of $60 \mathrm{kD}$ and contains 3.5 leucine-rich repeats (LRR) with conserved flanking sequences. In the LRR domain, LGI1 has the highest homology with a number of transmembrane and extracellular proteins which function as receptors and adhesion proteins. $L G I 1$ is predominantly expressed in neural tissues, especially in brain; its expression is reduced in low grade brain tumors and it is significantly reduced or absent in malignant gliomas. Its localization to the $10 q 24$ region, and rearrangements or inactivation in malignant brain tumors, suggest that LGI1 is a candidate tumor suppressor gene involved in progression of glial tumors.
\end{abstract}

Keywords: tumor suppressor gene; human chromosome 10; gene rearrangements; chromosome translocation; glioma; leucine-rich repeat

\section{Introduction}

Multiple genetic alterations are involved in the development and progression of malignant brain tumors. Frequently these events involve the functional loss of a tumor suppressor gene(s) which can occur as a result of either mutation, deletion or as a result of structural chromosome rearrangement. Loss of heterozygosity ( $\mathrm{LOH}$ ) studies, and the identification of consistent chromosome rearrangements, frequently serve to implicate a particular region of the genome in tumorigenesis (Cavenee et al., 1983; Ponder, 1988). Cytogenetic and molecular studies indicate that loss of one complete copy of chromosome 10 is the most common event in high-grade gliomas, presumably exposing a recessive mutation(s) in the remaining allele(s) of a critical tumor suppressor gene(s).

*Correspondence: JK Cowell

Received 25 June 1998; revised 28 September 1998; accepted 9 October 1998
Rearrangement and loss of at least some parts of the second copy of chromosome 10, especially in the 10q23-26 region, has been demonstrated in approximately $80 \%$ of glioblastoma multiforme (GBM) tumors (Bigner and Vogelstein, 1990; James et al., 1988; Karlbom et al., 1993; Rasheed et al., 1992). These changes are rarely seen in low-grade gliomas. Extensive analysis performed by several groups has identified at least three distinct regions of $\mathrm{LOH}$ on chromosome 10 (Albarosa et al., 1996; Karlbom et al., 1993; Rasheed et al., 1995). This data indicates that multiple genes on chromosome 10 are associated with the genesis and progression of malignant brain tumors. Recently, two candidate tumor suppressor genes, PTEN/MMAC (Li et al., 1997; Steck et al., 1997) and DMBT (Mollenhauer et al., 1997), have been isolated from the $10 \mathrm{q} 23$ and $10 \mathrm{q} 25-26$ regions, respectively. Mutations and deletions in each of the genes were found in approximately $25 \%$ of GBMs ( $\mathrm{Li}$ et al., 1997; Rasheed et al., 1997; Steck et al., 1997). These observations suggest that there may still be other genes in $10 \mathrm{q}$ which are important for tumorigenesis.

Cloning genes interrupted by chromosome translocations has proved to be a useful method for the identification of genes important in tumorigenesis (Clark et al., 1994; Ohta et al., 1996). Using this approach we have recently identified a glioblastoma cell line, T98G, which carries a $\mathrm{t}(10 ; 19)(\mathrm{q} 24 ; \mathrm{q} 13)$ translocation and no normal copy of chromosome 10 (Chernova and Cowell, 1998). Retention of only translocated copies of chromosome 10 in these tumor cells suggests that the primary event was whole chromosome loss and that the second event is specific gene inactivation as a result of the structural chromosome rearrangement. To investigate this possibility, we previously identified YAC clones from chromosomes 10 and 19 which crossed the translocation breakpoints in T98G glioblastoma cells (Chernova and Cowell, 1998). Here we describe the isolation and characterization of a novel gene from chromosome 10 , encoding a leucine-rich repeat-containing protein, which is associated with this translocation. Normal expression of this gene is highly specific for neural tissue and is absent, or significantly down-regulated, in malignant gliomas but not in low grade gliomas. We have called this gene LGII (Leucinerich gene- Glioma Inactivated).

\section{Results}

\section{Isolation of the LGI1 gene}

In a FISH analysis of the $\mathrm{t}(10 ; 19)(\mathrm{q} 24 ; \mathrm{q} 13)$ rearrangement from GBM cell line T98G (Chernova and Cowell, 
1998), we demonstrated that the non-chimeric, chromosome 10-specific YAC, 912c7, crossed the translocation breakpoint. From an analysis of overlapping YACs spanning this region, and YACs prepared by fragmenting 912c7, it was demonstrated that D10S185 and NIB1686 were the closest proximal and distal markers to the breakpoint, respectively (Chernova and Cowell, 1998). To define the position of the chromosome 10 breakpoint more accurately, a series of somatic-cell hybrids have now been generated between T98G cells and mouse 3 T3 cells. PCR analysis of individual hybrid clones identified two hybrids, TGF3 and TGF7, which apparently contained the der(19) and der(10) chromosomes, respectively, but not the homologous normal chromosomes. The presence of these derivative chromosomes was confirmed using FISH with paints for human chromosomes 10 and 19 (data not shown). These hybrid clones were used in all subsequent PCR analyses of the translocation breakpoint and allowed us to determine the presence/absence of individual STSs markers on the derivative chromosomes. This analysis allowed us to determine the precise position of the breakpoints relative to the physical map of the region (Figure 1a). We found that D10S185 lies above the breakpoint and NIB1686 lies below the breakpoint. One other marker, IB1099, which has been mapped to YAC 912c7, produced an amplification product which was the same size from both human and mouse DNA and so could not be positioned relative the breakpoint. Both IB1099 and D10S185, however, did map to a $225 \mathrm{~kb}$ fragmented YAC, F36 (Figure 1), which was shown by FISH to cross the 10q24 breakpoint (data not shown), indicating that D10S185 and IB1099 lay in the vicinity of the breakpoint.

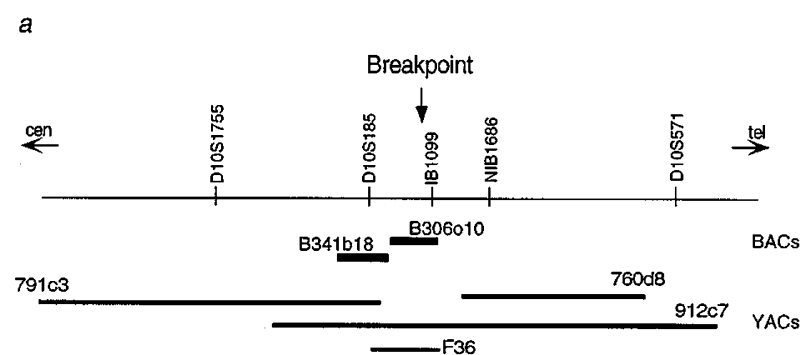

$b$

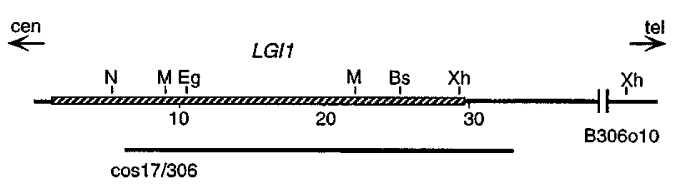

Figure 1 Summary of the physical map surrounding the 10q24 breakpoint region in $\mathrm{T} 98 \mathrm{G}$ cells. In (a) the orientation of individual YACs relative to the STS map of the region is shown. YAC F36 is a subclone from 912c7 both of which cross the translocation breakpoint. BACs 306010 and $341 \mathrm{~b} 18$ were isolated with IB1099 and D10S185 respectively, and by FISH 306010 crosses the breakpoint. In (b) the genomic position of LGII gene (shown as a hatched bar), within 306o10, is shown relative to the restriction enzyme map of the region. This analysis shows that cosmid $17 / 306$, which also crosses the breakpoint, contains most of the genomic structure of LGI1. The selected restriction endonuclease sites are: Bs, BssHII; Eg, EagI; M, MluI; N, NarI; Xh, XhoI. cen., centromere; tel., telomere
To obtain smaller clones which crossed the translocation breakpoint we used PCR primers for D10S185 and IB1099 to screen a human BAC library and isolated one BAC for each marker (Figure 1). FISH analysis demonstrated that BAC 306010, which contained IB1099, crosses the breakpoint but that BAC 341b18, which contains D10S185, hybridized exclusively to the (der)10 and so, did not cross the breakpoint (data not shown). FISH analysis of normal chromosomes confirmed that BAC 306010 localizes to $10 \mathrm{q} 24$ and is not chimeric. The IB1099 STS is one of the gene-based STSs which was derived from short sequences of $3^{\prime}$ untranslated regions of random, uncharacterized human brain cDNAs (Berry et al., 1995). Homology searches of the EST database using the IB1099 sequence identified three clones from the IMAGE consortium (Lennon et al., 1996). The longest clone, 35825, which was approximately $2.0 \mathrm{~kb}$, was sequenced on both strands. This sequence shows no homologies in the databases. Using the 35825 cDNA as a probe, and a combination of rare cutting restriction endonucleases which recognized $\mathrm{CpG}$-rich sequences, we generated a restriction map of BAC 306010 and demonstrated that most of the $\mathrm{CpG}$-rich sites cluster within a $30 \mathrm{~kb}$ region which also contained the 35825 cDNA (Figure 1b). Pulse field gel analysis of BAC 306 10 demonstrated that it was $170 \mathrm{~kb}$ long. To obtain smaller genomic clones, and to confirm the translocation of the LGII gene, BAC306 was subcloned into the pWE15 cosmid vector. FISH analysis of cosmid 17/306, which contained the LGII gene, showed the presence of specific hybridization signal on both derivative chromosomes (data not shown) demonstrating that this cosmid clone crossed the translocation breakpoint.

Although our primary aim was to isolate the chromosome 10 gene associated with the $t(10 ; 19)$ translocation in $\mathrm{T} 98 \mathrm{G}$ cells, we also analysed the translocation breakpoint region on chromosome 19. Previously we demonstrated that the CEPH YAC, 75le12, crossed the $\mathrm{t}(10 ; 19)(\mathrm{q} 24 ; \mathrm{q} 13)$ translocation breakpoint in T98G (Chernova and Cowell, 1998). This YAC, however, was clearly chimeric and, in addition, it contained an internal deletion making it unsuitable for use in further analysis. Using the somatic cell hybrid analysis with the PCR primers specific for STSs and genes which had been mapped to the YAC 751e12 region allowed us to position the chromosome 19 breakpoint to a relatively small region flanked by the ATP4A and APLP1 genes (Chernova and Cowell, 1998) according to the chromosome 19 map compiled by Ashworth et al. (1995). Using primers from the APLP1 gene, we isolated BAC clone, 316i22. FISH analysis demonstrated that this BAC crossed the translocation breakpoint and confirmed its location at $19 q 13.1$. Knowing the approximate position of the breakpoint allowed us to use sequence data recently released by the LLNL Human Genome Center for the chromosome 19q13.1 region (unpublished, see www-bio.Ilnl.gov/genome/genome. html) to create a set of PCR primers for more detailed analysis of the somatic cell hybrids. We found that the breakpoint occurred within a $50 \mathrm{~kb}$ region, which is spanned by cosmid F25965 and is flanked by cosmids F24109 and F19541 (Figure 2). Individual primer pairs, which were designed from throughout the region defined by these three cosmids, 
were used in a PCR analysis of the somatic cell hybrids, TGF3 and TGF7. This analysis demonstrated that the proximal part of cosmid F24109, including the U2AF gene, was present only on the $\operatorname{der}(19)$ chromosome and so lay above the breakpoint (Figure 2 ). The distal part of cosmid F19541, extending from nucleotide 14400, was detected only on the $\operatorname{der}(10)$ chromosome and so is translocated from chromosome 19. However, all of the PCR products from: (1) the distal end of cosmid F24109, (2) the entire cosmid F25965 and (3) the proximal portion of cosmid F19541, were detected on both derivative chromosomes, suggesting that duplication of this region had occurred during the evolution of this rearrangement. Although this secondary rearrangement complicated further analysis of the chromosome 19 breakpoint region, we found that one of the consequences of the translocation/rearrangement is the interruption of a hypothetical proline oxidase-like gene (accession number U95090) which was identified in cosmid F19541 as a result of the LLNL sequence analysis. Further analysis of this predicted gene in tumor samples, however, will be required to determine whether it has a role in tumorigenesis.

\section{Expression and structure of LGI1 gene}

To analyse the expression profile of LGII, clone 35825 was used to probe a Northern blot containing RNA

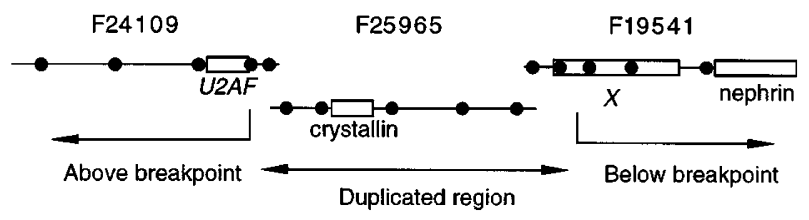

Figure 2 Cosmid map of the region spanning the $19 \mathrm{q} 13.1$ breakpoint in T98G. Cosmids F24109, F25965 and F19541 (accession numbers AD000671, AC002398 and U95090, respectively) are not drawn to scale. The position of the PCR-based DNA markers (filled circles) used to characterize the position of the $19 \mathrm{q} 13.1$ breakpoint using somatic cell hybrid analysis is indicated. The genes identified by their DNA sequence are; $U 2 A F$, alpha-B crystallin and nephrin; $X$, is a predicted gene similar to proline oxidase from multiple human tissues (Figure 3a). Transcripts were only detected in brain and skeletal muscle but not in heart, kidney, lung, placenta, liver, or pancreas. In brain and skeletal muscle, two mRNA species were detected; an abundant transcript which was approximately $2.4 \mathrm{~kb}$ and a $1.6 \mathrm{~kb}$ transcript which was much less abundant. This smaller transcript may represent a splicing variant of the gene. However, using the more sensitive RT - PCR procedure we detected low levels of LGI1 mRNA in heart, liver and pancreas. Analysis of RNA isolated from peripheral nerve showed levels of LGII mRNA which were intermediate between that seen in brain and other tissues. From this analysis it seems probable that the LGII mRNA detected in skeletal muscle originates from the peripheral nerves present in this tissue. Northern blot analysis of RNA derived from several different regions of human brain revealed a widespread expression of both transcripts, although with different intensity (Figure 3b). The highest abundance was found in total brain, cerebral cortex, hippocampus, and putamen. The lowest expression was detected in corpus callosum. The levels of expression were intermediate in the other regions.

The complete $1.8 \mathrm{~kb}$ sequence from the 35825 cDNA and overlapping IMAGE clones, 44117, 43427 and 47189, was established. The compiled consensus gene sequence contained a $1.5 \mathrm{~kb}$ open reading frame and a relatively short, $262 \mathrm{bp}, 3^{\prime}$ untranslated region, although the initiation methionine was still missing (Figure 4). Sequencing data revealed that at least three EST clones, including the 35825 cDNA, contained unspliced introns at their $5^{\prime}$-ends. To obtain the most $5^{\prime}$ sequence, an oligonucleotide designed from close to the $5^{\prime}$ end of clone 35825 (see primers GTmR in Materials and methods) were used in a $5^{\prime}$-RACE experiment using human brain Marathon-Ready cDNA (Clontech) as a template. The resultant PCR products were cloned into the pGEM-T vector and two clones were analysed. DNA sequencing of the longest clone, 5'RACE, confirmed its overlap with cDNA 35825 (Figure 4) and identified the initiating methionine codon of LGII. To obtain a full length cDNA clone, a fetal brain cDNA library was screened, resulting in the isolation of five positive clones. The longest clone hFB6d has a $2.3 \mathrm{~kb}$ insert and overlaps with the $5^{\prime} \mathrm{RACE}$ clones and

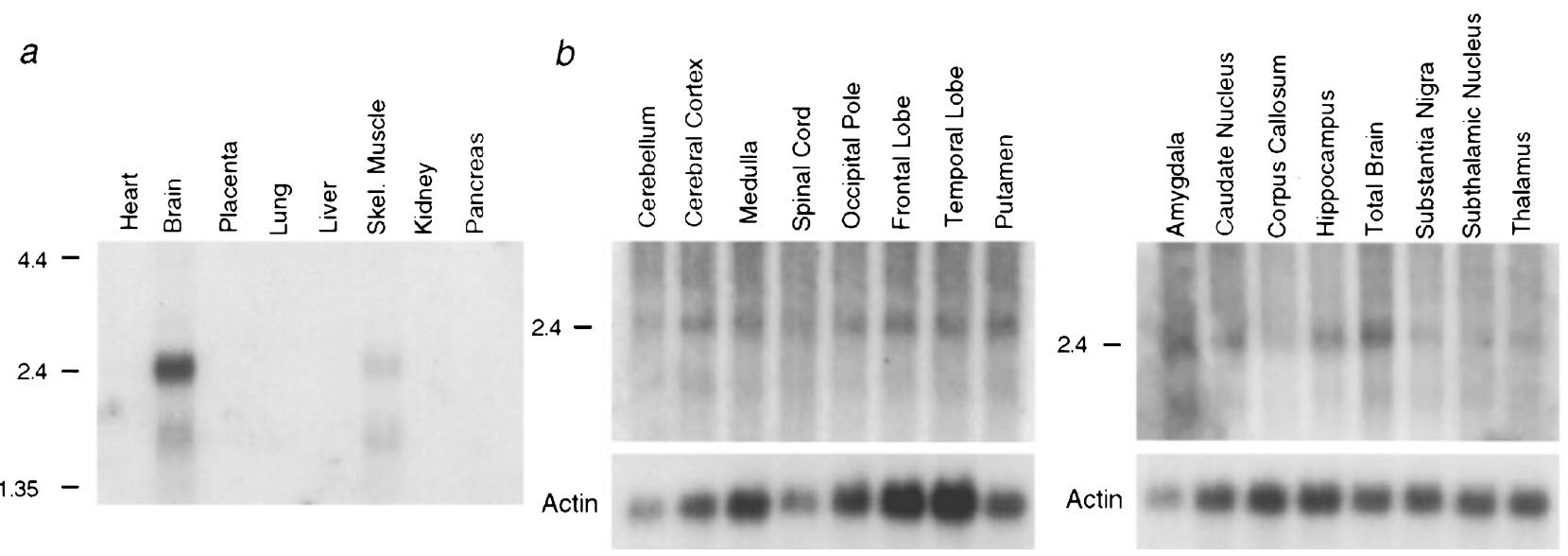

Figure 3 LGII expression in human tissues. Northern blots, containing poly(A) ${ }^{+}$RNA (2 $\mu$ g) from (a) multiple tissues or (b) different brain regions, were probed with the $35825 \mathrm{cDNA}$ insert. Transcripts of approximately 2.4 and $1.6 \mathrm{~kb}$ were detected in most brain regions and skeletal muscle. In (b, lower panels) the same filter membranes were reprobed with the beta-actin probe as a loading control 
identifies an additional EST sequence, D45285 (see Figure 4), in GDB. Analysis of these clones produced the final 2254 bp consensus cDNA sequence (Figure 5), which was consistent with the size of the LGII polyadenylated transcript detected by Northern blot analysis (see Figure 3), suggesting that this represents the full-length cDNA. The complete cDNA sequence, therefore, contains a $1674 \mathrm{bp}$ open reading frame which starts at position 225 with an ATG codon and terminates with TGA stop codon at position 1895 (Figure 5). A polyadenylation site (AATAAA) is located in the $3^{\prime}$-untranslated region, 20 nucleotides upstream of the poly-A tail. Three ATTTA motives, which are potentially involved in mRNA destabilization (Chen and Shyu, 1995), were also found in the 3'untranslated region.

The predicted protein sequence produced a 557 amino acid precursor polypeptide with a calculated molecular mass of $64 \mathrm{kD}$ (Figure 5). The protein amino terminus contains a stretch of hydrophobic amino acids which represents a signal peptide with a predicted cleavage site between Gly34 and Lys35. The molecular mass of the mature LGII protein, after the cleavage of the signal peptide, is $60 \mathrm{kD}$. Another hydrophobic segment (amino acids 288-309) represents a putative transmembrane domain. These structural features indicate that $L G I I$ is a potential transmembrane protein with the amino terminus located outside the cell. A search for motifs inside the gene revealed the presence of three and a half tandemly arrayed leucine-rich repeats (LRRs) in the amino-terminus of LGII. These LRRs are flanked on both sides by conserved cysteine clusters. The LRRs in LGII consist of 24 amino acids and have a strong homology (Figure 6) to the LRRs of the slit, tall, osteomodulin, biglycan $(38-41 \%$ identity and $58-$ $67 \%$ similarity over LRR region) and other small proteoglycans, which belong to the ' $\mathrm{F}-20$ ' family of the LRR-containing proteins (for review see Buchanan and Gay, 1996; Kobe and Deisenhofer, 1994). These proteins are characterized by the conservation of a phenylalanine at position 20 in the LRR. The presence of cysteine clusters flanking the LRRs is highly conserved in these transmembrane and extracellular proteins (Figure 6c,d) which function as adhesion proteins and receptors. Two potential N-glycosylation sites are located in the C-terminal flanking region (Asn192) and upstream of the transmembrane region (Asn277). The cytoplasmic portion of $L G I 1$ revealed no

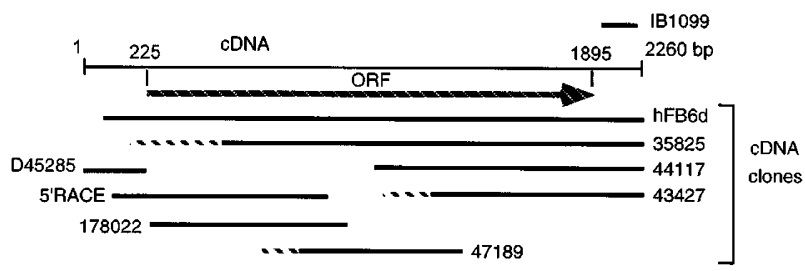

Figure 4 Relationship between the individual LGI1 cDNA clones (identified by their IMAGE \#) used to compile the full length sequence. The position of the open reading frame (ORF) and IB1099 STS used to isolate the gene are shown. hFB6d is the longest cDNA clone isolated from a human fetal brain cDNA library; $5^{\prime} \mathrm{RACE}$ is the longest cDNA we obtained from RACE and D45285 is an EST derived from a cerebral cortex cDNA. The broken lines at the $3^{\prime}$ ends of three cDNAs indicates the presence of intronic sequences homology to known proteins. However, there are potential phosphorylation sites for cyclic AMPdependent protein kinase (Ser313), tyrosine kinase

GATCOCTOCCATCTCACAGIACCTCACAOGTCTCTTOCOOOCAOCAGTOCATTOCTOGAS 60 OAAGGACAACCTCACGAATCAOCTOCAGGTCICIGITTTGAAAAACCAGACATACACACG 120 CAGAGCAAAOSOGIGCACTOCTATGTGACCTGITCTTIAGACCAAACAATCPCCATCTGA 180 AITCCAGAAGCOCTGTTCATGGTIGGGCATATTTTCTCGACTOCATOGAATCAGAAACAA 240 $M E S E$ E R

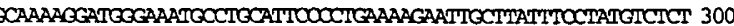
$S K R M G N$ A C I P L K B I A Y E L C L L TATCTOOOCTTTTGCICACIGACOOCAACAAACCAGOCAACOCAAAATOOOCTOOOGIGT 360

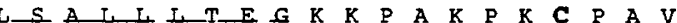
GIACTIGIACCAAAGATAATOCTITATGTGACAATGCCAGATCCATTCCACOCACOGTIC 420

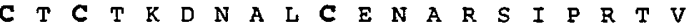
CTCCIGATGTTATCTCATTATOCTITGTGAGATCTGGTTITACTGAAATCTCACAAGOCA 480

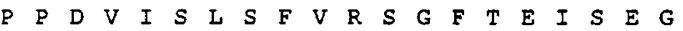
GITITTIATTCACOOCATCOCTGCACCICTTGITATTCACATCGAACTCCITIGATGTGA 540 $\begin{array}{llllllllllllllllllll}S & F & L & F & T & P & S & L & Q & L & L & L & F & T & S & N & S & F & D & V\end{array}$ TCAGIGATCATCCITTIATTGGTCITCOACATCTAGAGTATTTATTCATAGAAAACAACA 600 $\begin{array}{lllllllllllllllllllll}I & S & D & D & A & F & I & G & L & P & H & L & E & Y & L & F & I & E & N & N\end{array}$ ACATCAAGTCAATITLAACACATACTIICOCOCGACTAAAGICATTAATTCACTTGACOC 660 $\begin{array}{llllllllllllllllllll}N & I & K & S & I & S & R & H & T & F & R & G & L & K & S & L & I & H & L & S\end{array}$ TTOCAAACAACAATCTOCAGACACTCOCAAAAGATATTTTCAAAGCOCIGGATTCITITAA 720 \begin{tabular}{llllllllllllllllllll}
$L$ & $A$ & $N$ & $N$ & $N$ & $L$ & $Q$ & $T$ & $L$ & $P$ & $K$ & $D$ & $I$ & $F$ & $K$ & $G$ & $L$ & $D$ & $S$ & $L$ \\
\hline
\end{tabular} CAAATGTOGAOCTGAGGGGTAATTCATTIAATTGTGACTGTAAACTGAAATOCCTAGTOG 780

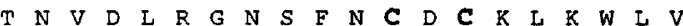
AATGCCITGCOCACAOCAATOCAACIGITGAACACATCTACTGCOAACOCCCCOCCACAAT 840 $\begin{array}{llllllllllllllllllll}E & W & L & G & H & T & N & A & T & V & E & D & I & Y & C & E & G & P & P & E\end{array}$ ACAACAACOOCAAAATCAATAGTCTCTOCICGAACATTTCGATTGCATCATTACAGAAT 900 $\begin{array}{llllllllllllllllllll}Y & K & K & R & K & I & N & S & L & S & S & K & D & F & D & C & I & I & T & E\end{array}$ TTIGCAAAGICTCAACAOCTCOCITIATCAATCATTGTOCATACACACITTTTCTTATTTCA 960

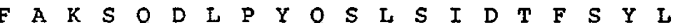
ATGATGAGTATGIAGICATCOCTCAGOCIITIACIGCAAAATOCATITIOCTIGAATGOG 1020 $\begin{array}{lllllllllllllllllllll}N & D & E & Y & V & V & I & A & O & P & F & T & G & K & C & I & F & L & E & W\end{array}$ ACCATGIGGAAAAGACCTTCCOGGATTATGACAACATIACAGCCACATDCACTGTAGIAT 1080 $\begin{array}{lllllllllllllllllllll}D & H & V & E & K & T & F & R & N & Y & D & N & I & T & G & T & S & T & V & V\end{array}$ GCAAGOCIATAGTCATIGAAACTCAGCTCTATGITATTGIGOCOCACCIGTTIGGIOCCT 1140 $C K P$ I V I E T $Q$ L $Y$ V I V A $O$ L $F$ G G CICACATCIATAAGOCACACAGTTTOCAAATAAATTCATAAAAATCCADCATPATICAAA 1200 $\begin{array}{lllllllllllllllllllll}S & H & I & Y & K & R & D & S & F & A & N & K & F & I & K & I & Q & D & I & E\end{array}$ TTCICAAAATCOCAAAACOCAATGACATTCAAACATTCAACATIGAAAACAACTGGIACT 1260

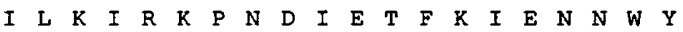
TTGITGTTOCIGACAGTICAAAAOCIOGITTTACTAOCATTTACAAATGCAACGGAAAOG 1320

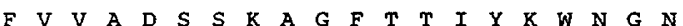
GATICIACTCCOATCAATOCITACACOOGIGGIACACOCACACIGATGIGCAATATCIAG 1380 $\begin{array}{llllllllllllllllllll}G & F & Y & S & H & O & S & L & H & A & W & Y & R & D & T & D & V & E & Y & L\end{array}$ AAATAGTCAGAACAOCTCAGACACTCACAACOCCTCATTTAATTCTGTCIAGTAGTTCOC 1440

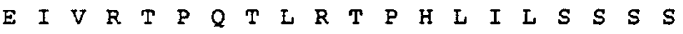
AGCGTOCIGIAATTTATCAGTGGAACAAACCAACACAATTATTCACTAAOCAAACTGACA 1500 $\begin{array}{llllllllllllllllllll}Q & R & P & V & I & Y & Q & W & N & K & A & T & Q & L & F & T & N & Q & T & D\end{array}$ TICCTAACATGCACGATGIGIACGCAGIGAAGCACITCICAGIGAAAGGGGACGIGIACA 1560

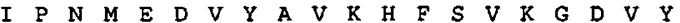
TTIGCTIGACAAGATTCATIGGTGATICCAAAGTCATGAAATGOOCAOOCTOIOUTIOC 1620 $\begin{array}{lllllllllllllllllllll}I & C & L & T & R & F & I & G & D & S & K & V & M & K & W & G & G & S & S & F\end{array}$ AGGATATTCAGAOCATCOCATCGCOAGGATCCATGGIGTTCCACOCTCITCAAATAAATA 1680

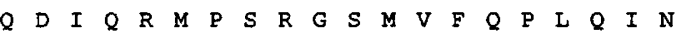
ATTACCAATATOCAATTCTTGCAAGIGATTACTOCTTIACTOAAGIGIATAACIOBCATG 1740 $\begin{array}{lllllllllllllllllllll}N & Y & Q & Y & A & I & L & G & S & D & Y & S & F & T & Q & V & Y & N & W & D\end{array}$ CAGAGAAGCCAAATTIGTGAAATTICAGCAATMAAATGTTCACOCACCAGATCAITCA 1800 $\begin{array}{llllllllllllllllllll}A & E & K & A & K & F & V & K & F & Q & E & L & N & V & Q & A & P & R & S & F\end{array}$ CACATGIGTCCATTAATAAGCGIPATTITCTTITTIGCTTCCAGITTITAAGCGAATACAC 1860

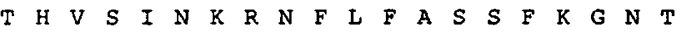
AGAITIPCAAACAIGTLATAGTTGACTIAACOBCATGACACACCAAATTCTGIGCCIGOC 1920

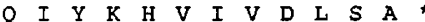

ATCAGAAATTTTCTACAGTACATGACOCOCATCAACTCAATOCATCATCACTCITCTTPT 1980 CACACTTGCAAATGATCOCTTTCAAACATTGACACTGCIAGAACOAAOCACTAOCAGTR 2040 TCTCCATOCTIAACTGIOCAGIOCAGTCATGIOCGAAGTTAOCITTIATAAACACAAAAT' 2100 TAAITGIGIAACTGITCTITGCAGIGAAGATGIGIAAATAACOGITTAATGGIATCIGIT 2160

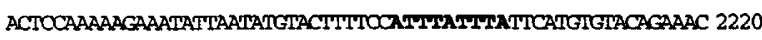
ACTOCCAAATAAAATGTTTACATTTTCITTCATA 2254

Figure 5 The human LGII cDNA nucleotide and deduced amino acid sequence. The predicted signal peptide is underlined with a broken line; the position of the 3.5 leucine-rich repeats are underlined with a solid line, and the conserved Cys residues in the regions flanking the LRR are indicated in bold. (*), TGA stop codon. A polyadenylation site (AATAAA) and ATTTAdestabilization motifs located in the $3^{\prime}$-UTR are also in bold 

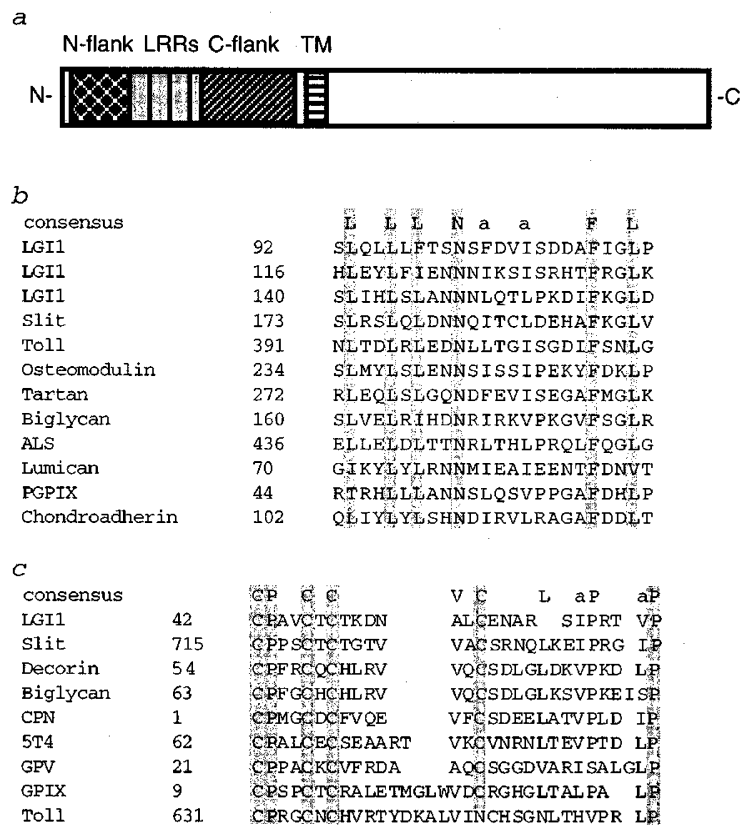

d

$\begin{array}{llll}\text { consensus } & c \text { a WL } \\ \text { LGI1 } 175 \text { FNCDCKLKWLVEWLGHTNATVEDIY CEGPPEYKKRKINSLSSKDFD }\end{array}$ Slit 453 PFICDCNLRWLADYLHKNP IETSGAR CESPKRMHRRRI ESLREEK FKC Tartan 379 PL SCDCRVMWL HNL LVAKNASODDVSELLICEF PERLRGE SLRHLNPAMMGC TRKC 163 FFNC SCD IRWMO LWOEOGEAKLNSONLY :C I NADGSOL PLF RMN ISO 5T 4295 PWV DEAHMADMVTWLKETEVVQGKDRLT THA YPEKMRNRVLLEINSADLD

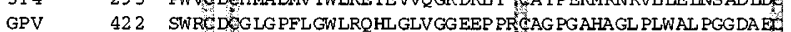

Figure 6 A schematic representation of the various domains of the $L G I 1$ protein is shown in (a). N-flank and C-flank indicate the cysteine-rich regions flanking the leucine-rich repeats (LRR); TM, transmembrane region. In (b), the comparative alignments of the three LRRs in LGII are compared with various other homologous proteins. Comparative alignments for the aminoflanking (c) and the carboxy-flanking (d) regions, relative to other LRR-containing proteins, are also shown. The most conservative, consensus residues are shown in gray boxes. ' $a$ ' represents aliphatic residues such as L, I, A, V, F, Y and $\mathrm{M}$. The consensus sequences have been reported previously (Buchanan and Gay, 1996; Kobe and Deisenhofer, 1994)

(Tyr384), and several sites for PKC and casein kinase II. From the results of this structural analysis, it became apparent that $L G I 1$ is a novel integral membrane protein belonging to the LRR-protein superfamily.

\section{Analysis of LGI1 in brain tumors}

To investigate the frequency of LGII rearrangements in glioblastoma cells, we used Southern blot analysis of DNA from seven glioblastoma cell lines (Figure $7 \mathrm{a}, \mathrm{b})$ digested with $X b a \mathrm{I}$ or BamHI. Rearrangements of $L G I 1$ were seen in two $(29 \%)$ cell lines, T98G and A172. Cell lines U87-MG, U118-MG, U251-MG, U373-MG, and GB-1, showed no abnormal bands. The rearrangement in the $\mathrm{T} 98 \mathrm{G}$ cells confirmed that $L G I 1$ is a target for the translocation in these cells. The rearranged fragment in A172 cells was different from that seen in T98G cells. FISH analysis of the chromosomes from the A172 cells, using the cosmid 17/306 which contains LGII, revealed an intrachromosomal rearrangement in 10q, possibly an inversion, which resulted in a more proximal location for LGII on the marker chromosome (in preparation). We also examined genomic DNAs from 19 primary GBM and four anaplastic gliomas for rearrangements of the LGII gene by blot hybridization. Genomic DNA from 9/23 (39\%) tumors, digested with the $X b a \mathrm{I}$ restriction endonuclease, showed abnormal bands. Representative examples of the rearranged bands are shown in Figure 7c. To determine whether any of the abnormal restriction fragments represent polymorphic variants, we analysed 17 control DNA samples, isolated from blood lymphocytes of normal individuals, using the XbaI enzyme. In the majority of these normal DNAs (15/ 17, 88\%), LGII cDNA hFB6d recognizes two high molecular weight bands, approximately $10 \mathrm{~kb}$ and $13 \mathrm{~kb}$ long. Two $(12 \%)$ of the DNA samples, however, showed an additional $19 \mathrm{~kb}$ band suggesting the possibility that these represent polymorphic variants (Figure 7c). The same $19 \mathrm{~kb}$ band was also seen in $13 \%$ of malignant glioma DNA. Even when the $19 \mathrm{~kb}$ band was excluded, however, the various rearranged restriction fragments were still detected in $26 \%$ (five GBMs and one anaplastic oligodendroglioma) of tumors, suggesting that they represent tumorspecific rearrangements.

Despite the abundant expression of $L G I 1$ in brain tissue, Northern blot analysis of RNA from glioblastoma cell lines failed to detect any $L G I I$-specific transcripts (data not shown) at this level of sensitivity. To investigate whether lower levels of expression could be detected, we used primers specific to different regions of the $L G I 1 \mathrm{cDNA}$ to perform RT-PCR using total RNA from glioblastoma cell lines and normal brain tissue. To increase the specificity of the RTPCR analysis, and therefore to avoid amplification from potential contaminating genomic DNA, only PCR primers amplifying across one or two splicing sites were used. PCR products of the expected sizes were generated from normal brain RNA, but not from RNA isolated from T98G and A172 cells (Figure 8). This lack of LGII expression suggests that the rearrangements in these cells were responsible for gene inactivation. GBM-specific PCR products were almost undetectable in any of the other glioblastoma cell lines.

We also examined a series of nine low grade gliomas, ten anaplastic gliomas and 15 glioblastoma multiforme by RT-PCR for $L G I I$ expression. For this, primary brain tumors were cultured in vitro for a few passages to enrich for tumor cells. All low grade gliomas (four juvenile pylocytic astrocytomas, two adult astrocytomas and three oligodendrogliomas) and one benign acoustic neuroma (schwannoma) had decreased but clearly detectable expression of $L G I 1$ mRNA when compared with normal brain RNA (Figure 8). In contrast, four/five anaplastic oligodendrogliomas had very low levels of $L G I 1$ expression and four/five anaplastic astrocytomas had no detectable LGII transcripts. Similarly, PCR analysis showed that three of $15(20 \%)$ GBM tumors were negative and the other $12(80 \%)$ tumors had very low levels of $L G I 1$ transcripts. Both the absent, or reduced, expression of the LGI1 gene in GBMs and anaplastic gliomas, together with the relatively frequent rearrangements of the genomic sequences and its localization in the region of frequent $\mathrm{LOH}$ on chromosome 10 in gliomas, suggests that LGII is a target gene for inactivation in malignant brain tumors. 

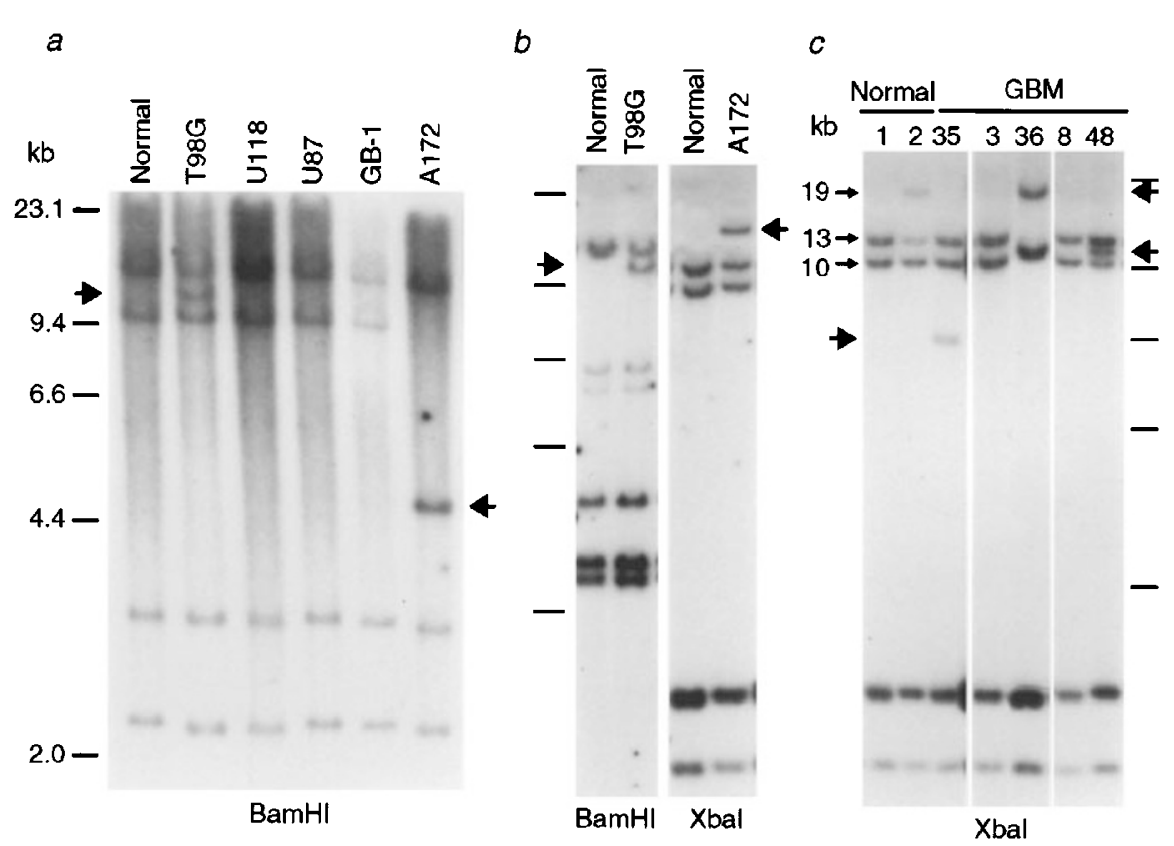

Figure 7 Southern blot analysis of the LGII gene in glioblastomas. Genomic DNAs from GBM cell lines and peripheral blood (normal control) were digested with BamHI or $X b a \mathrm{I}$ and probed with (a) cos17/306 or (b) hFB6d cDNA. In (c), genomic DNAs from primary GBMs (patients $35,3,36,8$ and 48 ) and normal samples were digested with $X b a \mathrm{I}$ and probed with the hFB6d cDNA. Arrows indicate the restriction fragments observed in normal DNA samples; lane 1 shows the restriction pattern $(10 \mathrm{and} 13 \mathrm{~kb})$ found in the majority of normal DNA samples, lane 2 shows the rare polymorphic variant indicated by the presence of an additional $19 \mathrm{~kb}$ band. Abnormal bands were detected in DNAs from the T98G and A172 cells, and GBM tumors 35, 36 and 48 (indicated by the arrowheads)

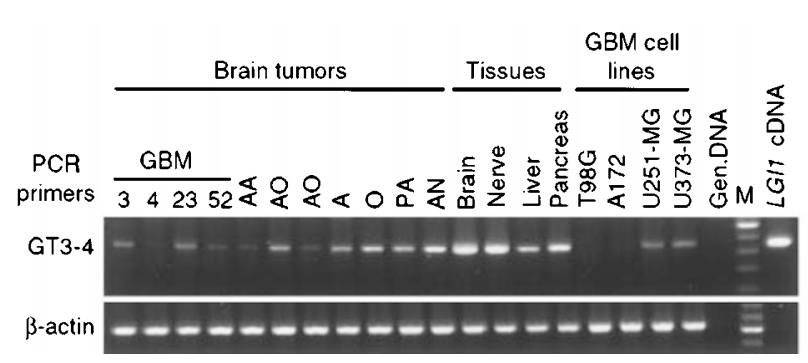

Figure 8 Analysis of LGI1 expression in various brain tumors, human tissues and glioblastoma cell lines using RT-PCR followed by agarose gel electrophoresis. The 450-bp GT3-4 product spans the interval between nucleotides $50 \ldots 509$ of the LGI1 cDNA (see Figure 5). A 600-bp RT-PCR product from beta-actin was used for normalization of cDNA levels. Lane 2 contains the sample from tumor CCF4 and is negative. GBM, glioblastoma; AA, anaplastic astrocytoma; AO, anaplastic oligodendroglioma; A, astrocytoma; O, oligodendroglioma; PA, pilocytic astrocytoma; AN, acoustic neuroma; Gen. DNA, human genomic DNA (negative control); M, 100-bp size marker

\section{Discussion}

We have used a positional cloning approach to isolate a novel gene, LGI1, which is interrupted by the $\mathrm{t}(10 ; 19)(\mathrm{q} 24 ; \mathrm{q} 13)$ translocation in the T98G glioblastoma cell line. LGII was localized to $10 \mathrm{q} 24$, a region which is commonly deleted in malignant gliomas (Albarosa et al., 1996; Karlbom et al., 1993; Rasheed et al., 1995) and other malignant tumors (Gray et al., 1995; Herbst et al., 1994; Peiffer et al., 1995). The highest levels of LGII expression is seen in different brain regions and at lower levels in peripheral nerve and skeletal muscle. Using RT-PCR, low levels of expression were detected in some other tissues (liver, pancreas, thymus).
We confirmed the rearrangement of LGII in T98G cells using Southern blot analysis and also detected rearrangements of the genomic copy of LGII in another GBM cell line, A172, and in six primary malignant gliomas. Analysis of chromosomes from A172 revealed a complex intrachromosomal rearrangement of one of the copies of chromosome 10. Because the ability to detect genomic rearrangements using blot hybridization with a cDNA probe depends greatly on a choice of restriction endonucleases used to digest the DNA, the exact frequency of rearrangements in tumors may still be higher.

Analysis of expression in brain tumors demonstrated reduced levels of LGII mRNA in low-grade pediatric and adult gliomas and in one schwannoma. In anaplastic gliomas (both, astrocytic and oligodendrocytic lineage) and glioblastoma multiforme tumors, however, LGII expression was absent or barely detectable, even using RT-PCR. A similar expression pattern was observed in GBM cell lines. Remarkably, in two glioblastoma cell lines, T98G and A172, in which LGI1 expression was completely lost, structural rearrangements in the LGII gene were observed. A limited cytogenetic analysis of primary tumors also identified one glioblastoma, CCF4, in which one copy of chromosome 10 was lost and the other was involved in a $\mathrm{t}(10 ; 11)(\mathrm{q} 24-25 ; \mathrm{q} 11)$ translocation (Chernova and Cowell, 1998). These tumor cells were also negative for LGI1 expression (see Figure 8). Although preliminary FISH analysis indicated that LGII does not cross the translocation breakpoint in CCF4 (unpublished observations), it seems likely that the relocation of $L G I I$ close to the pericentric heterochromatin in the centromere of chromosome 11, may affect expression of $L G I 1$ in this tumor. Blot hybridization analysis of DNA from the other glioblastoma cell lines showing 
very weak LGII expression, however, did not show changes in the restriction pattern. Similar observations of reduced expression in the absence of deletions or mutations have been reported for the BRCAl gene in non-hereditary forms of breast cancer (Thompson et al., 1995), the p16INK4/MTS1 gene in a number of tumors (Asamoto et al., 1997; Marchini et al., 1997), and the $D C C$ gene in neuroblastoma (Kong et al., 1997). One of the mechanisms of down-regulation of the p16INK4 gene was shown to be due to hypermethylation (El et al., 1997; Myohanen et al., 1998). However, because down-regulation of p16INK4 was also observed in the absence of hypermethylation in some cases (Ryan et al., 1998; Schmidt et al., 1997), it seems that other, as yet identified, mechanisms may also be involved. Further analysis of the promoter region of the LGII gene and its methylation pattern will be required to understand the mechanisms of its down-regulation in malignant tumors.

The LGII cDNA encodes a predicted 557 amino acid polypeptide. The deduced protein contains a signal peptide and a transmembrane domain, suggesting a cytoplasmic membrane localization of the mature $60 \mathrm{kDa}$ protein. LGII contains 3.5 LRRs flanked on both sides by conserved cysteine-rich regions. The LRR structure allows LGII to be classified as a new member of the group of extracellular LRR proteins. The presence of the LRRs flanked by the conserved cysteine-rich regions is a structural feature of the extra-cytoplasmic domains of these secreted or transmembrane proteins (Buchanan and Gay, 1996; Kobe and Deisenhofer, 1994). Many of these proteins are involved in control of cell proliferation, differentiation, cell-cell and cell-matrix recognition and adhesion. The known function of the LRR domains is either protein-protein interaction or specific receptor-ligand binding. LRRs have been identified as the high affinity binding sites in the receptors for neurotrophin (Windisch et al., 1995a,b) and gonadotrophin (Braun et al., 1991) as well as in the proteoglycans (Svensson et al., 1995). A number of LRR-containing proteins such as slit, toll, tartan, connectin and the Trk family of proteins are involved in the development and differentiation of the neural system (Chang et al., 1993; Halfon et al., 1995; Meakin and Shooter, 1992; Nose et al., 1997; Rothberg et al., 1990).

The evidence for a glioma-related tumor suppressor gene in 10q24 is now overwhelming. However, the long arm of chromosome 19 also shows frequent LOH in brain tumors, especially oligodendrogliomas and oligoastrocytomas where $\mathrm{LOH}$ for $19 \mathrm{q}$ markers occurs in $70-80 \%$ of tumors (Kraus et al., 1995; von Deimling et al., 1994). The frequency of LOH on $19 \mathrm{q}$ in GBM, however, is smaller. Because of this observation, however, the question arises whether the $\mathrm{t}(10 ; 19)$ translocation in $\mathrm{T} 98 \mathrm{G}$ cells also interrupts a gene on chromosome 19 which may be important for tumorigenesis. The minimal, commonly deleted region has been assigned to $19 \mathrm{q} 13.3$ and spans about $1 \mathrm{Mb}$ (Rosenberg et al., 1996). Our cytogenetic interpretation of the translocation breakpoint in T98G cells is that it occurs in 19q13.1 (Chernova and Cowell, 1998) and this has now been confirmed by the molecular studies here, which places it proximal to the commonly deleted region. Unfortunately, even though the position of the
$19 \mathrm{q}$ breakpoint in $\mathrm{T} 98 \mathrm{G}$ is still a provocative observation, the presence of a secondary rearrangements at the site of the breakpoint makes it difficult to establish the exact consequences of the rearrangement at this time. The fact that $L G I 1$ is interrupted by chromosome translocations and is almost invariably inactivated in malignant gliomas, indicates that this gene is probably the most important gene partner in this translocation. This suggestion is further supported by the observation that rearrangements of LGII occur in tumor cells which do not show structural rearrangements involving chromosome 19.

Recently, two candidate tumor suppressor genes, PTEN/MMAC (Li et al., 1997; Steck et al., 1997) and DMBT (Mollenhauer et al., 1997), have been isolated from the 10q23 and 10q25-26 regions, respectively. PTEN/MMAC has been shown to be mutated in $17-$ $24 \%$ of primary GBMs, $14 \%$ breast cancer tumors, and $25 \%$ of kidney carcinomas (Steck et al., 1997). This gene, however, clearly maps outside of the region of frequent $\mathrm{LOH}$ in gliomas. The localization of another candidate gene, DMBT1, does coincide with the region of frequent $\mathrm{LOH}$ in 10q25-26. Intragenic, homozygous deletions in DMBT1 gene were detected in $23 \%$ of GBMs (Mollenhauer et al., 1997). Nevertheless, unlike $L G I 1$, it is clear that neither of these genes are inactivated in the majority of GBM. In summary we believe that, because LGII is localized to the $10 \mathrm{q} 24$ region, shows a brain specific pattern of expression, and is inactivated and rearranged in malignant gliomas, it is a strong candidate tumor suppressor gene involved in the malignant progression of glial tumors.

\section{Materials and methods}

\section{Tumor samples and cell lines}

Primary tumor samples were obtained from an unselected series of patients treated at Cleveland Clinic Foundation. Tumors were graded according to the revised WHO classification (Kleihues et al., 1993). Primary explant cultures were established in MEM containing $10 \%$ fetal calf serum, from tumor samples as described elsewhere (Cowell and Franks, 1984). Following outgrowth of the tumor cells, they were passaged four to eight times following a $1: 3$ split ratio to increase cell numbers and to enrich for tumor cells. Established glioblastoma cell lines were obtained from ATCC, except for GB1 cells, which were a gift from Dr B Barna.

\section{$B A C s$ and $c D N A$ isolation}

The human BAC library and I.M.A.G.E Consortium (LLNL) cDNA clones (ESTs) were purchased from Research Genetics, Inc. (Huntsville, AL, USA). The BAC library was screened using PCR with primers for IB1099 and D10S185. A human fetal brain cDNA library (Clontech, Palo Alto, CA, USA) was screened by hybridization using cDNA clone 35825 (EST). Inserts from positive clones were subcloned into pBluescript SKII $(-)$ and sequenced. 5'RACE-products were generated using Marathon-Ready cDNA from human brain (Clontech) according to the manufacturer's instructions. The $L G I 1$-specific primer used in the $5^{\prime} \mathrm{RACE}$ procedure was GTmR (5'-AGGTCTTGTCCACATGGTCC-3'). PCR products were cloned into the pGEM-T vector (Promega, Madison, WI, USA). 
DNA sequencing of all cDNA clones was performed on both strands using an ABI377 automated DNA sequencer (Applied Biosystems, Foster, CA, USA) by the CCF sequencing core facility. Information for EST clones and expressed sequence tags (dbEST) was obtained from public databases using the network service at the National Center for Biotechnology Information (NCBI). cDNA and predicted protein sequences were analysed using a variety of generally available prediction programs, in particular, BLAST, BLOCK, and TMpred. GenBank accession number for the human LGII gene is AF055636.

\section{Expression analyses}

Northern blots containing the RNA from the tissues of interest were obtained from Clontech. Hybridizations were carried out at $68^{\circ} \mathrm{C}$ according to the ExpressHyb-protocol provided by the manufacturer. Expression analyses in brain tumors and cell lines was done by RT-PCR. Total RNA was isolated from primary tumor cultures using the Tryzol reagent (Life Technologies). The first-strand cDNA was generated from total RNA using random primers and Superscript revertase (Life Technologies) according to manufacturer's protocol. A $1 / 10$ fraction of the firststrand cDNA was amplified with LGI1-specific primers designed from different exons such that they did not generate a PCR-product from genomic DNA. LGI1-specific primer pair sequences were as follows: GT1 5'-CATTGCTGGAGCGAGGAGAA-3' and GT2, 5'-GAGCTG-

\section{References}

Albarosa R, Colombo BM, Roz L, Magnani I, Pollo B, Cirenei N, Giani C, Conti AM, DiDonato S and Finocchiaro G. (1996). Am. J. Hum. Genet., 58, $1260-$ 1267.

Asamoto M, Iwahori Y, Okamura T, Shirai T and Tsuda H. (1997). Jpn. J. Clin. Oncol., 27, $22-25$.

Ashworth LK, Batzer MA, Brandriff B, Branscomb E, de Jong P, Garcia E, Garnes JA, Gordon LA, Lamerdin JE and Lennon G, Mohrenweiser H, Olsen AS, Slezak T and Carrano AV. (1995). Nature Genet., 11, 422-427.

Berry R, Stevens TJ, Walter NA, Wilcox AS, Rubano T, Hopkins JA, Weber J, Goold R, Soares MB and Sikela JM. (1995). Nature Genet., 10, 415-423.

Bigner SH and Vogelstein B. (1990). Brain Pathol., 1, $12-18$.

Braun T, Schofield PR and Sprengel R. (1991). EMBO J., 10, $1885-1890$.

Buchanan SG and Gay NJ. (1996). Prog. Biophys. Mol. Biol., 65, $1-44$.

Cavenee WK, Dryja TP, Phillips RA, Benedict WF, Godbout R, Gallie BL, Murphree AL, Strong LC and White RL. (1983). Nature, 305, $779-784$.

Chang Z, Price BD, Bockheim S, Boedigheimer MJ, Smith R and Laughon A. (1993). Dev. Biol., 160, 315-332.

Chen CY and Shyu AB. (1995). Trends Biochem. Sci., 20, $465-470$.

Chernova OB and Cowell JK. (1998). Cancer Genet. Cytogenet., in press.

Clark J, Rocques PJ, Crew AJ, Gill S, Shipley J, Chan AM, Gusterson BA and Cooper CS. (1994). Nat. Genet., 7, $502-508$.

Cowell JK and Franks LM. (1984). Int. J. Cancer, 33, $657-$ 667.

El NA, Lai S, Clayman G, Lee JK, Luna MA, Goepfert H and Batsakis JG. (1997). Am. J. Pathol., 151, 1767-1774.

Gray IC, Phillips SM, Lee SJ, Neoptolemos JP, Weissenbach J and Spurr NK. (1995). Cancer Res., 55, 4800-4803.

CAGCGATGGCGTGA-3'; GT3 5'-CGAACTCCTTTGATGTGATC-3' and GT4 5'-CTTCGCAGTAGATGTCTTCA; GT5 5'-GGACCATGTGGACAAGACCT-3' and GT6 5'-CACATCAGTGTCCCTGTACCA-3'. After an initial denaturation $\left(94^{\circ} \mathrm{C}\right.$ for $\left.3 \mathrm{~min}\right), 35$ cycles of amplification $\left(94^{\circ} \mathrm{C}\right.$ for $1 \mathrm{~min}, 57^{\circ} \mathrm{C}$ for $30 \mathrm{~s}, 72^{\circ} \mathrm{C}$ for $1 \mathrm{~min}$ ) were carried out, followed by a final extention for $5 \mathrm{~min}$ at $72^{\circ} \mathrm{C}$. For a normalization control, $1 / 20$ fraction of the same samples was amplified using primers specific for the $\beta$-actin cDNA (Raff et al., 1997).

\section{Southern blot analysis}

Samples containing $7 \mu \mathrm{g}$ of genomic DNA were digested with different restriction enzymes and electrophoresed on $0.8 \%$ agarose gels, transferred to nylon membranes, and hybridized with the ${ }^{32} \mathrm{P}$-labeled cDNA probes following standard protocols. The hybridization mixture for cosmid $17 / 306$ contained $50 \mu \mathrm{g} / \mathrm{ml}$ sheared human DNA to compete out repetitive sequences. Hybridization was carried out in $5 \times \mathrm{SSC}$ at $65^{\circ} \mathrm{C}$, with a final wash at $0.2 \times \mathrm{SSC}$ at $65^{\circ} \mathrm{C}$.

\section{Acknowledgements}

We thank Drs D Miller, $G$ Barnett and $\mathbf{J}$ Hahn for providing tumor samples. This work was supported by grant CA76457 from the NIH and in part by the Rose-Ella Burkhardt Endowment Fund.

Halfon MS, Hashimoto C and Keshishian H. (1995). Dev. Biol., 169, 151- 167.

Herbst RA, Weiss J, Ehnis A, Cavenee WK and Arden KC. (1994). Cancer Res., 54, 3111-3114.

James CD, Carlbom E, Dumanski JP, Hansen M, Nordenskjold M, Collins VP and Cavenee WK. (1988). Cancer Res., 48, 5546-5551.

Karlbom AE, James CD, Boethius J, Cavenee WK, Collins VP, Nordenskjold M and Larsson C. (1993). Hum. Genet., 92, $169-174$.

Kleihues P, Burger PC and Scheithauer BW. (1993). Brain Pathol., 3, 255-268.

Kobe B and Deisenhofer J. (1994). Trends Biochem. Sci., 19, $415-421$

Kong XT, Choi SH, Inoue $\mathrm{A}, \mathrm{Xu} \mathrm{F}$, Chen $\mathrm{T}$, Takita J, Yokota J, Bessho F, Yanagisawa M, Hanada R, Yamamoto K and Hayashi Y. (1997). Cancer Res., 57, $3772-3778$.

Kraus JA, Koopmann J, Kaskel P, Maintz D, Brandner S, Schramm J, Louis DN, Wiestler OD and von Deimling A. (1995). J. Neuropath. Exp. Neurol., 54, 91-95.

Lennon G, Auffray C, Polymeropoulos M and Soares MB. (1996). Genomics, 33, 151-152.

Li J, Yen C, Liaw D, Podsypanina K, Bose S, Wang SI, Puc J, Miliaresis C, Rodgers L, McCombie R, Bigner SH, Giovanella BC, Ittmann M, Tycko B, Hibshoosh H, Wigler MH and Parsons R. (1997). Science, 275, $1943-$ 1947.

Marchini S, Codegoni AM, Bonazzi C, Chiari S and Broggini M. (1997). Br. J. Cancer, 76, 146-149.

Meakin SO and Shooter EM. (1992). Trends Neurosci., 15, $323-331$.

Mollenhauer J, Wiemann S, Scheurlen W, Korn B, Hayashi Y, Wilgenbus KK, von DA and Poustka A. (1997). Nat. Genet., 17, $32-39$. 
Myohanen SK, Baylin SB and Herman JG. (1998). Cancer Res., 58, $591-593$.

Nose A, Umeda T and Takeichi M. (1997). Development, 124, $1433-1441$.

Ohta $\mathrm{M}$, Inoue $\mathrm{H}$, Cotticelli MG, Kastury $\mathrm{K}$, Baffa $\mathrm{R}$, Palazzo J, Siprashvili Z, Mori M, McCue P and Druck T, Croce CM, and Huebner K. (1996). Cell, 84, 587-597.

Peiffer SL, Herzog TJ, Tribune DJ, Mutch DG, Gersell DJ and Goodfellow PJ. (1995). Cancer Res., 55, 1922-1926.

Ponder B. (1988). Nature, 335, 400-402.

Raff T, van der Giet M, Endemann D, Wiederholt T and Paul M. (1997). Biotechniques, 23, 456-460.

Rasheed BK, Fuller GN, Friedman AH, Bigner DD and Bigner SH. (1992). Genes Chrom. Cancer, 5, 75-82.

Rasheed BK, McLendon RE, Friedman HS, Friedman AH, Fuchs HE, Bigner DD and Bigner SH. (1995). Oncogene, 10, $2243-2246$

Rasheed BK, Stenzel TT, McLendon RE, Parsons R, Friedman AH, Friedman HS, Bigner DD and Bigner SH. (1997). Cancer Res., 57, 4187-4190.

Rosenberg JE, Lisle DK, Burwick JA, Ueki K, von DA, Mohrenweiser HW and Louis DN. (1996). Oncogene, 13, $2483-2485$.
Rothberg JM, Jacobs JR, Goodman CS and Artavanis TS. (1990). Genes Dev., 4, 2169-2187.

Ryan A, AI JR, Mulligan KT and Jacobs IJ. (1998). Gynecol. Oncol., 68, 14-17.

Schmidt EE, Ichimura K, Messerle KR, Goike HM and Collins VP. (1997). Br. J. Cancer, 75, $2-8$.

Steck PA, Pershouse MA, Jasser SA, Yung WK, Lin H, Ligon AH, Langford LA, Baumgard ML, Hattier T, Davis T, Frye C, Hu R, Swedlund B, Teng DH and Tavtigian SV. (1997). Nat. Genet., 15, 356-362.

Svensson L, Heinegard D and Oldberg A. (1995). J. Biol. Chem., 270, 20712-20716.

Thompson ME, Jensen RA, Obermiller PS, Page DL and Holt JT. (1995). Nat. Genet., 9, 444-450.

von Deimling A, Nagel J, Bender B, Lenartz D, Schramm J, Louis DN and Wiestler OD. (1994). Int. J. Cancer, 57, $676-680$.

Windisch JM, Marksteiner R, Lang ME, Auer B and Schneider R. (1995a). Biochemistry, 34, 11256-11263.

Windisch JM, Marksteiner R and Schneider R. (1995b). J. Biol. Chem., 270, 28133-28138. 